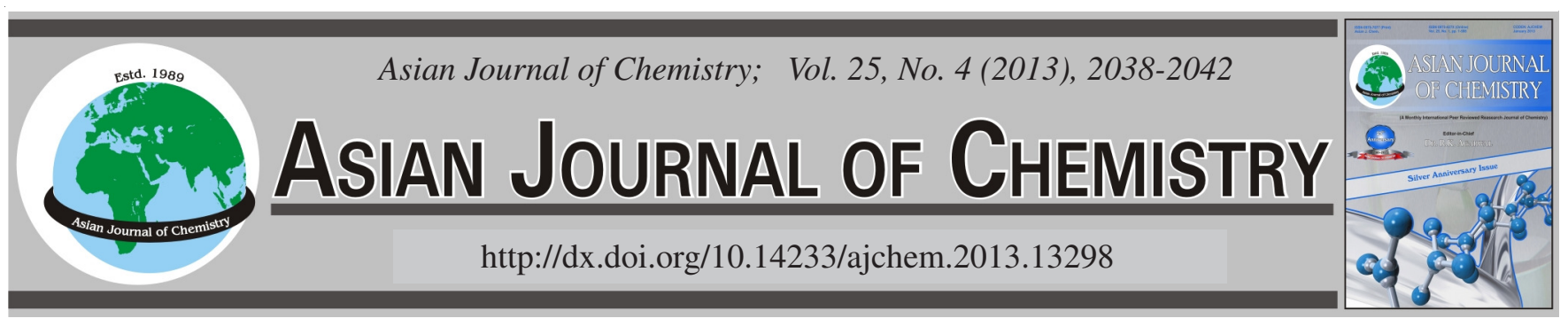

\title{
Kinetic of Methane Hydrate Formation in Micro- and Nanodroplets
}

\author{
Mehrdad Manteghian ${ }^{*}$, Reza Dorosti and Abolfazl Mohammadi
}

Department of Chemical Engineering, Tarbiat Modares University, Tehran, Iran

*Corresponding author: Fax: +98 21 88005040; Tel: +98 21 82883333; E-mail: manteghi@modares.ac.ir

\begin{abstract}
In this research, the kinetic of hydrate formation from a microdroplet or nanodroplet is investigated. The shrinking core model is used for predicting of hydrate growth on a droplet. In this model, it assumed that the nucleation was started on the outer surface of water droplet and the direction of hydrate growth is into the center of the droplet. Diffusion of the gas molecules through the gas film surrounding the droplet, diffusion through the hydrate layer and reaction with the outer surface of unreacted water is the steps of hydrate formation in shrinking core model. The reaction rate constant of methane molecules with water droplet $(\mathrm{k})$ is extracted from literature. Using shrinking core model showed that, in nanodroplets and droplets smaller than $1 \mu \mathrm{m}$, reaction of gas molecules with water droplet is the main resistance in the hydrate formation. By increasing the size of water droplets, the resistance of diffusion through the hydrate film was increased and in droplet larger than $100 \mu \mathrm{m}$, the main resistance of hydrate formation was diffusion of gas molecules. By increasing the temperature, the effect of chemical reaction in hydrate formation resistances was increased.
\end{abstract}

Key Words: Nanodroplet, Microdroplet, Hydrate, Kinetic, Shrinking core model, Mass transfer, Methane.

\section{INTRODUCTION}

Gas hydrates, or clathrate hydrates, are ice-like crystalline compounds formed by the inclusion of low molecular diameter non-polar or slightly polar molecules inside cavities formed by water molecules ${ }^{1}$. Currently, gas hydrate technology is being widely used in the fields of storage and transportation of natural gas, seawater desalination, carbon dioxide sequestration and cold storage air-conditioning. Therefore, it is substantially important to perform studies on gas hydrate ${ }^{2}$. Slow formation rate of natural gas hydrate is a critical problem hindering the industrial application of this technology. One way to increase the hydrate formation rate is using of surfactants. At our previous works, we have used various surfactants for increasing the rate of dissolution and hydrate formation ${ }^{3-5}$.

Electrospraying is a method of droplet production. Droplets, which produced by this method are highly charged, that prevents their coagulation and promotes self-dispersion. In electrospraying method the size of the droplets can be controlled to some extent by voltage and flow rate ${ }^{6}$. The kinetic modeling of hydrate formation so far has been developed based on a stirred tank batch, where a reactor containing water maintained at hydrate forming conditions is injected with gas and agitated to produce hydrates systems ${ }^{7,8}$. Recently, advanced observation and measuring methods have been adopted in the researches of hydrate formation kinetics worldwide ${ }^{9-13}$. Lee $e t$ $a l .{ }^{14}$ studied the gas hydrate formation and decomposition of water droplets using methane-ethane and methane-propane mixtures. Ohmura et al. ${ }^{15}$ reported the visual observation of the formation and growth of structure-H hydrate crystals on a water droplet. In this research, we will investigate the kinetic of hydrate formation from a micro- and nanodroplet.

\section{EXPERIMENTAL}

Fig. 1 shows the proposed mechanism of hydrate formation from a droplet surrounding by gas molecules.
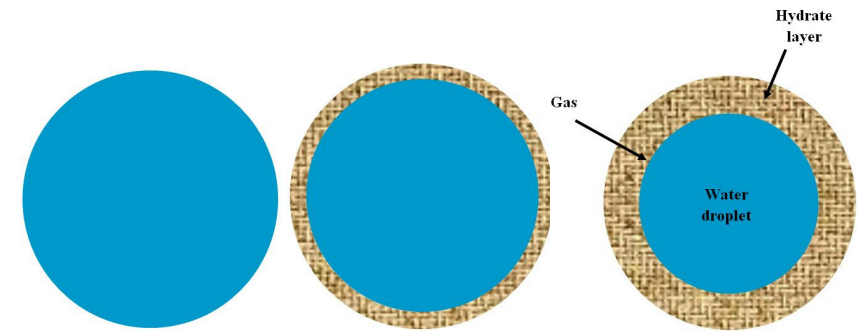

Fig. 1. Proposed mechanism of hydrate formation from a water droplet; a) Initial droplet that surrounded by gas molecules; b) A thin film of hydrate that is formed from the outer surface of initial droplet; c) Growth of hydrate layer from surface to the center of droplet

In shrinking core model, hydrate formation of a water droplet consist of three steps ${ }^{16}$ : (1) Diffusion of the gas 
molecules (A) through the gas film surrounding the droplet; (2) Diffusion of gas molecules through the hydrate layer; (3) Reaction of gas molecules with the outer surface of unreacted water.

The reaction of hydrate formation is shown in eqn. (1):

$$
\mathrm{A}(\text { gas })+\mathrm{bB} \text { (water droplet }) \rightarrow \mathrm{sS} \text { (hydrate) }
$$

The resistance of gas film is negligible in comparison of two other resistances. Diffusion through the hydrate layer, hydrate formation reaction or combination of these two steps is the rate-controller in hydrate formation process. From the eqn. (1) it can be written:

$$
\begin{gathered}
\mathrm{dn}_{\mathrm{B}}=\mathrm{b} \cdot \mathrm{dn}_{\mathrm{A}} \\
\mathrm{dn}_{\mathrm{B}}=\mathrm{d}\left(\rho_{\mathrm{B}} \mathrm{V} / \mathrm{M}_{\mathrm{B}}\right)=\frac{\rho_{\mathrm{B}}}{\mathrm{M}_{\mathrm{B}}} \mathrm{d}\left(\frac{4}{3} \pi \mathrm{r}_{\mathrm{C}}^{3}\right)=\frac{4 \pi \rho_{\mathrm{B}} \mathrm{r}_{\mathrm{c}}^{2}}{\mathrm{M}_{\mathrm{B}}} \mathrm{dr} \mathrm{r}_{\mathrm{c}}
\end{gathered}
$$

where, $\rho_{B}, M_{B}, V$ and $r_{C}$ are density, molecular weight, instant volume and radius of a water droplet respectively.

If diffusion of gas A through the gas film being the ratecontroller of hydrate formation process, the flux of water conversion to hydrate can obtain from eqn. (4):

$$
\begin{gathered}
\frac{-1}{\mathrm{~S}_{\mathrm{ex}}} \frac{\mathrm{dn}_{\mathrm{B}}}{\mathrm{dt}}=\frac{-1}{4 \pi \mathrm{R}^{2}} \frac{\mathrm{dn}_{\mathrm{B}}}{\mathrm{dt}}=\frac{-\mathrm{b}}{4 \pi \mathrm{R}^{2}} \frac{\mathrm{dn}_{\mathrm{A}}}{\mathrm{dt}} \\
=\mathrm{bk}_{\mathrm{G}}\left(\mathrm{C}_{\mathrm{Ag}}-\mathrm{C}_{\mathrm{As}}\right)=\mathrm{bk}_{\mathrm{G}} \mathrm{C}_{\mathrm{Ag}}
\end{gathered}
$$

In this equation, $S_{e x}$ is the initial surface of droplet, $R$ is the initial radius of droplet, $\mathrm{b}$ is the stoichiometric coefficient in eqn. (1), $\mathrm{k}_{\mathrm{G}}$ is the mass transfer coefficient between gas molecules and water droplet, $\mathrm{C}_{\mathrm{Ag}}$ is the concentration of $\mathrm{A}$ in gas bulk and $\mathrm{C}_{\mathrm{As}}$ is the concentration of gas $\mathrm{A}$ on the outer layer of hydrate $(r=R)$. If gas film being the main resistance, we can assume that $C_{A s}=0$. By substituting the eqn. (3) in eqn. (4) and integrating of it:

$$
t=\frac{\rho_{B} R}{3 b k_{G} M_{B} C_{A g}}\left[1-\left(\frac{r_{C}}{R}\right)^{3}\right]
$$

If diffusion through the hydrate layer being the main resistance of the hydrate formation process, by writing the steady- state mole balance for the control volume showing in Fig. 2, eqn. (6) can be obtained as following:

$$
\text { A. }\left.N_{\mathrm{Ar}}\right|_{\mathrm{r}}-\left.\mathrm{A} \cdot \mathrm{N}_{\mathrm{Ar}}\right|_{\mathrm{r}+\mathrm{dr}}=0 \Rightarrow \frac{\mathrm{d}}{\mathrm{dr}}\left(\mathrm{A} \cdot \mathrm{N}_{\mathrm{Ar}}\right)=0
$$

That $A$ is the surface of hydrate layer at radius $r$ and $N_{A r}$ is the mole flux of gas $\mathrm{A}$ at radius $\mathrm{r}$.

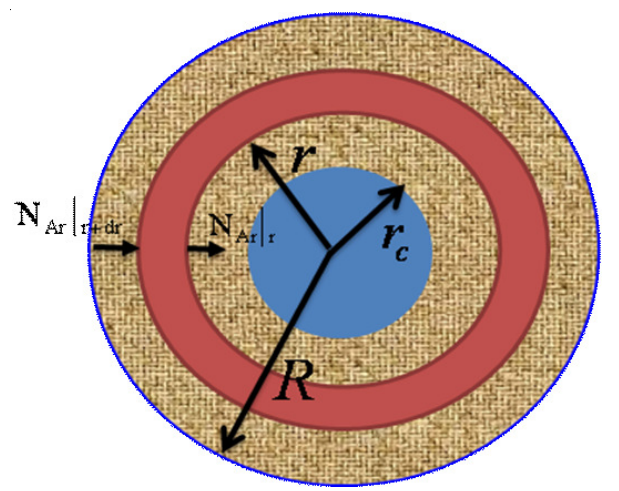

Fig. 2. Control volume for the state that diffusion through the hydrate film is rate-controller of hydrate formation process
In this state it is assumed that the rate of diffusion through the hydrate layer in any instant is equal to the rate of reaction of A:

$$
-\frac{\mathrm{dn}_{\mathrm{A}}}{\mathrm{dt}}=4 \pi \mathrm{r}^{2} \cdot \mathrm{N}_{\mathrm{Ar}}=4 \pi \mathrm{R}^{2} \cdot \mathrm{N}_{\mathrm{As}}=4 \pi \mathrm{r}_{\mathrm{c}}^{2} \cdot \mathrm{N}_{\mathrm{Ac}}=\text { cte }
$$

where, $\mathrm{N}_{\mathrm{Ac}}$ and $\mathrm{N}_{\mathrm{As}}$ are the mole fluxes of gas $\mathrm{A}$ at $\mathrm{r}_{\mathrm{C}}$ and $\mathrm{R}$ respectively. Fick's law for the diffusion is given in eqn. (8):

$$
\mathrm{N}_{\mathrm{Ar}}=\mathrm{D}_{\mathrm{e}} \frac{\mathrm{dC}_{\mathrm{A}}}{\mathrm{dr}}
$$

where, $D_{e}$ is the effective diffusivity of gas $A$ in the hydrate layer. Substituting eqn. (8) in to the eqn. (7) yields:

$$
-\frac{\mathrm{dn}_{\mathrm{A}}}{\mathrm{dt}}=4 \pi \mathrm{r}^{2} \mathrm{D}_{\mathrm{e}} \frac{\mathrm{dC}_{\mathrm{A}}}{\mathrm{dr}}=\text { cte }
$$

By integrating of eqn. (9) from $R$ to $r_{C}$ :

$$
\begin{gathered}
-\frac{\mathrm{dn}_{\mathrm{A}}}{\mathrm{dt}} \int_{\mathrm{R}}^{\mathrm{r}_{\mathrm{c}}} \frac{\mathrm{dr}}{\mathrm{r}^{2}}=4 \pi \mathrm{D}_{\mathrm{e}} \int_{\mathrm{C}_{\mathrm{As}}=\mathrm{C}_{\mathrm{Ag}}}^{\mathrm{C}_{\mathrm{Ac}}=0} \mathrm{dC}_{\mathrm{A}} \\
-\frac{\mathrm{dn}_{\mathrm{A}}}{\mathrm{dt}}\left(\frac{1}{\mathrm{r}_{\mathrm{c}}}-\frac{1}{\mathrm{R}}\right)=4 \pi \mathrm{D}_{\mathrm{e}} \mathrm{C}_{\mathrm{Ag}}
\end{gathered}
$$

By combining the eqns. (2) and (3):

$$
\mathrm{dn}_{\mathrm{A}}=\mathrm{dn}_{\mathrm{B}} / \mathrm{b}=\frac{4 \pi \rho_{\mathrm{B}} \mathrm{r}_{\mathrm{c}}^{2}}{\mathrm{bM}_{\mathrm{B}}} \mathrm{dr}_{\mathrm{c}}
$$

By substituting the eqn. (12) in the eqn. (11) and integrating of it, the relation of unreacted water droplet radius with time will obtain:

$$
t=\frac{\rho_{\mathrm{B}} \mathrm{R}^{2}}{6 \mathrm{bD}_{\mathrm{e}} \mathrm{M}_{\mathrm{B}} \mathrm{C}_{\mathrm{Ag}}}\left[1-3\left(\frac{\mathrm{r}_{\mathrm{C}}}{\mathrm{R}}\right)^{2}+2\left(\frac{\mathrm{r}_{\mathrm{C}}}{\mathrm{R}}\right)^{3}\right]
$$

If reaction of gas molecules with water droplet being the rate-controller, according to Fig. 3, it is assumed that the concentration of $\mathrm{A}$ in hydrate layer, gas film and gas bulk is equal:

$$
\mathrm{C}_{\mathrm{A}}=\mathrm{C}_{\mathrm{As}}=\mathrm{C}_{\mathrm{Ac}}=\mathrm{C}_{\mathrm{Ag}}
$$

The reaction of hydrate formation occurs in $r=r_{c}$, so the reaction rate obtains from eqn. (15).

$$
\frac{-1}{\mathrm{~A}_{\mathrm{c}}} \frac{\mathrm{dn}_{\mathrm{A}}}{\mathrm{dt}}=\frac{-1}{4 \pi \mathrm{r}^{2} \mathrm{c}} \frac{\mathrm{dn}_{\mathrm{A}}}{\mathrm{dt}}=\mathrm{kC}_{\mathrm{Ag}}
$$

That $\mathrm{k}$ is the reaction rate constant.

By combining the equations (2) and (15):

$$
\frac{-1}{A_{c}} \frac{\mathrm{dn}_{B}}{d t}=\frac{-b}{A_{c}} \frac{\mathrm{dn}_{\mathrm{A}}}{\mathrm{dt}}=\frac{-\mathrm{b}}{4 \pi \mathrm{r}_{\mathrm{c}}^{2}} \frac{\mathrm{dm}_{\mathrm{A}}}{\mathrm{dt}}=\mathrm{bkC}_{\mathrm{Ag}}
$$

By substituting the eqn. (16) in the eqn. (12) and integrating of it:

$$
\mathrm{t}-\frac{\rho_{\mathrm{B}} \mathrm{R}}{\mathrm{bkM}_{\mathrm{B}} \mathrm{C}_{\mathrm{Ag}}}\left[1-\frac{\mathrm{r}_{\mathrm{C}}}{\mathrm{R}}\right]
$$

If all three steps have a high resistance for hydrate formation, the required time for reducing the radius of unreacted water droplet obtain by summing the time of three above steps:

$$
\begin{gathered}
\mathrm{t}=\frac{\rho_{\mathrm{B}} \mathrm{R}}{\mathrm{bM}_{\mathrm{B}} \mathrm{C}_{\mathrm{Ag}}}\left\{\frac{1}{3} \frac{1}{\mathrm{k}_{\mathrm{G}}}\left[1-\left(\frac{\mathrm{r}_{\mathrm{C}}}{\mathrm{R}}\right)^{3}\right]+\frac{1}{6} \frac{\mathrm{R}}{\mathrm{D}_{\text {eff }}}\right. \\
\left.\left[1-3\left(\frac{\mathrm{r}_{\mathrm{C}}}{\mathrm{R}}\right)^{2}+2\left(\frac{\mathrm{r}_{\mathrm{C}}}{\mathrm{R}}\right)^{3}\right]+\frac{1}{\mathrm{k}}\left[1-\frac{\mathrm{r}_{\mathrm{C}}}{\mathrm{R}}\right]\right\}
\end{gathered}
$$




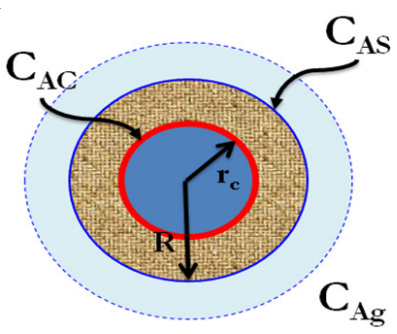

Fig. 3. Various concentrations of gas molecules for state that chemical reaction is the rate-controller of hydrate formation process

\section{RESULTS AND DISCUSSION}

Generally, the resistance of diffusion in gas film is negligible in hydrate formation process. Thus in this paper it is assumed that the main resistances of hydrate formation are diffusion in hydrate layer and reaction between gas molecules and water droplet. Bergeron et al. ${ }^{17}$ presented the reaction rate constant of hydrate formation at three temperatures. The data is given in Table-1.

\section{TABLE-1}

REACTION RATE CONSTANTS FOR METHANE HYDRATE FORMATION AT VARIOUS TEMPERATURES ${ }^{17}$

\begin{tabular}{lccc}
\hline Average temperature $(\mathrm{K})$ & 275.1 & 277.1 & 279.1 \\
\hline Reaction rate constant $\left(\times 10^{-8} \mathrm{~m} / \mathrm{s}\right)$ & $8.3 \pm 0.5$ & $21.5 \pm 3.9$ & $61.5 \pm 4.8$
\end{tabular}

As respects the methane molecules forms the structure I of hydrate and assuming that the reaction is complete, the constant of $b$ in eqn. (1) will be equal to 5.75. The required time for complete conversion of water droplet to gas hydrate $(\tau)$ can be obtained by substituting the $r_{c}=0$ in eqns. (13) and (17). $\tau_{\mathrm{D}}$ and $\tau_{\mathrm{r}}$ represent the $\tau$ for the states that the ratecontroller of hydrate formation being diffusion and reaction, respectively.

$$
\begin{gathered}
\tau_{D}=\frac{\rho_{B} R^{2}}{6 b D_{e} M_{B} C_{A g}} \\
\tau_{r}=\frac{\rho_{B} R}{b k M_{B} C_{A g}}
\end{gathered}
$$

We defined the $\mathrm{D}_{\mathrm{a}}$ as the ratio of the reaction rate constant to the effective diffusivity of gas A in hydrate film.

$$
\mathrm{D}_{\mathrm{a}}=\frac{\mathrm{k}}{\mathrm{D}_{\mathrm{e}}}
$$

For various values of effective diffusivity in the range of $10^{-13}$ $10^{-10} \mathrm{~m}^{2} / \mathrm{s}$, the amount of $\mathrm{D}_{\mathrm{a}}$ was calculated for three temperatures of 275.1, 277.1 and 279.1 K and was given in Table-2.

TABLE-2

VALUES OF $D_{a}$ FOR THE VARIOUS EFFECTIVE DIFFUSIVITIES IN THE RANGE OF $10^{-13}-10^{-10} \mathrm{~m}^{2} / \mathrm{s}$ AND THE REACTION RATE CONSTANTS LISTED IN TABLE-1

\begin{tabular}{lccc}
\hline Average temperature $(\mathrm{K})$ & 275.1 & 277.1 & 279.1 \\
\hline $\mathrm{D}_{\mathrm{a}}\left(\mathrm{m}^{-1}\right)$ & $8.3 \times 10^{2}-$ & $21.5 \times 10^{2}-$ & $61.5 \times 10^{2}-$ \\
& $8.3 \times 10^{5}$ & $21.5 \times 10^{5}$ & $61.5 \times 10^{5}$ \\
\hline
\end{tabular}

According to the eqn. (21) by increasing the effective diffusivity, rate of the reaction rate constant $\left(D_{a}\right)$ decreases.

To obtain the effect of droplet size on the rate-controlling mechanisms of mass transfer, the droplets with the radius of
$100 \mathrm{~nm}-100 \mu \mathrm{m}$ have been studied. Figs. 4-6 depict the amounts of $\tau_{\mathrm{D}}$ and $\tau_{\mathrm{r}}$ for all data of $\mathrm{D}_{\mathrm{a}}$ that are listed Table- 2 . By comparison of the Figs. 4-6 (specially in the sections of C of this figures), it can be understood that increasing of the temperature at the constant pressure, droplet radius and $\mathrm{D}_{\mathrm{a}}$, would decrease the effect of chemical reaction on the ratecontrolling of the hydrate formation. From Table-1, it can be seen that by increasing the temperature of system, the rate constant of hydrate formation reaction was increased and according to eqn. (20), increasing of k causes decrease of $\tau_{\mathrm{r}}$.
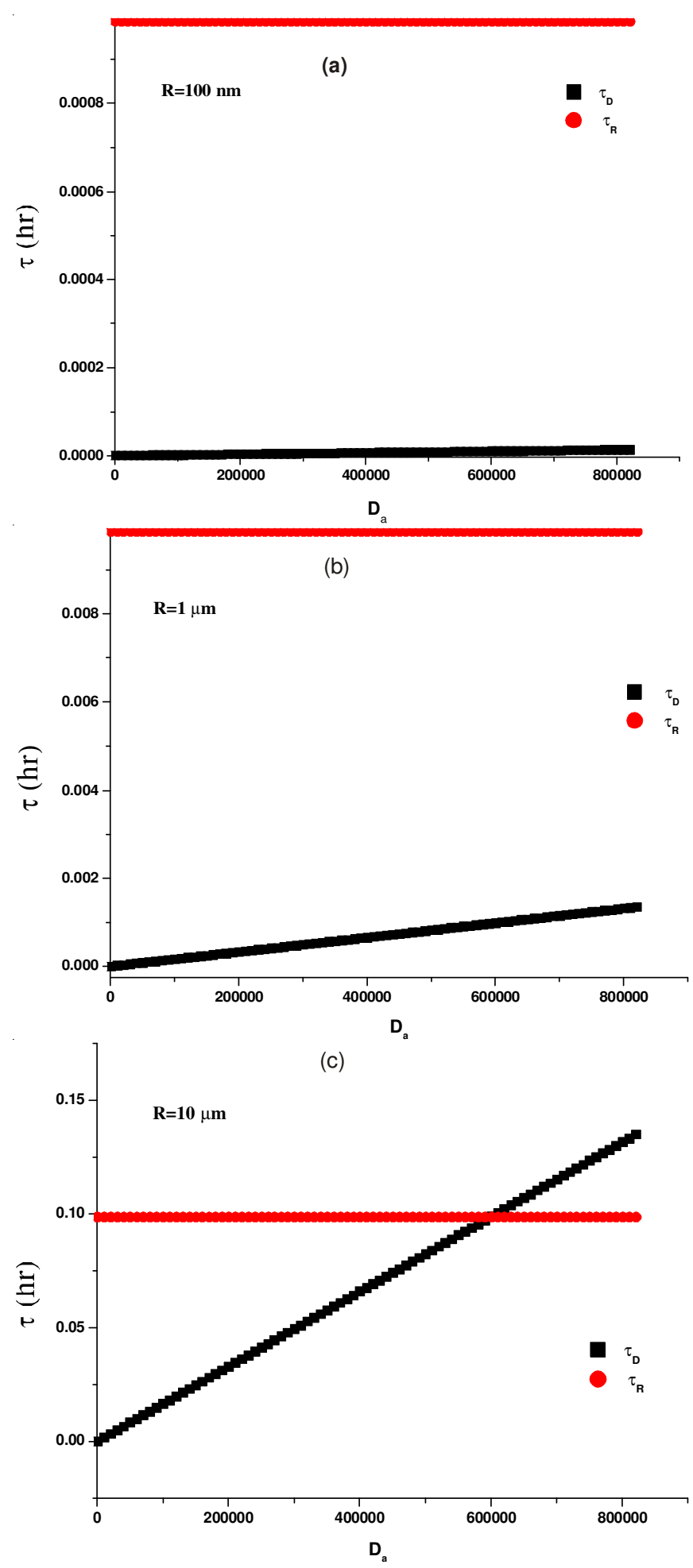


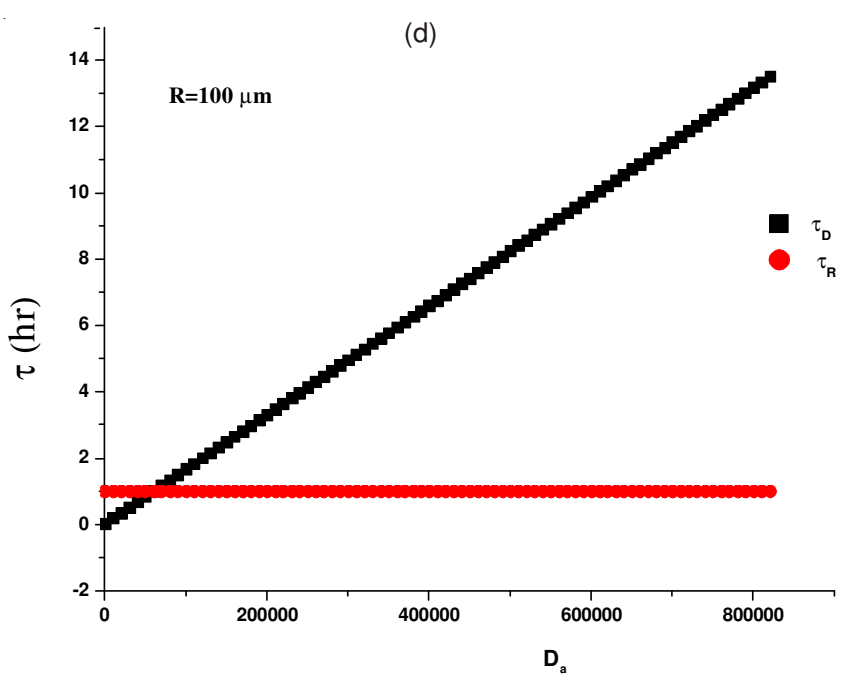

Fig. 4. Required time $(\tau)$ for complete conversion of water droplet to hydrate at 75 bar and $275.1 \mathrm{~K}$ and at various $\mathrm{D}_{\mathrm{a}}$; a) $\mathrm{R}=100 \mathrm{~nm}$; b) $\mathrm{R}=1 \mu \mathrm{m} ; \mathrm{c}) \mathrm{R}=10 \mu \mathrm{m} ; \mathrm{d}) \mathrm{R}=100 \mu \mathrm{m}$

As can be seen in each Figs. 4-6, by increasing the initial radius of water droplet at constant temperature and pressure, both diffusion and reaction resistances was increased but increases in diffusion resistance is more than the increases in reaction resistance. For example in Fig. 4-a $(T=275.1 \mathrm{~K}$ and
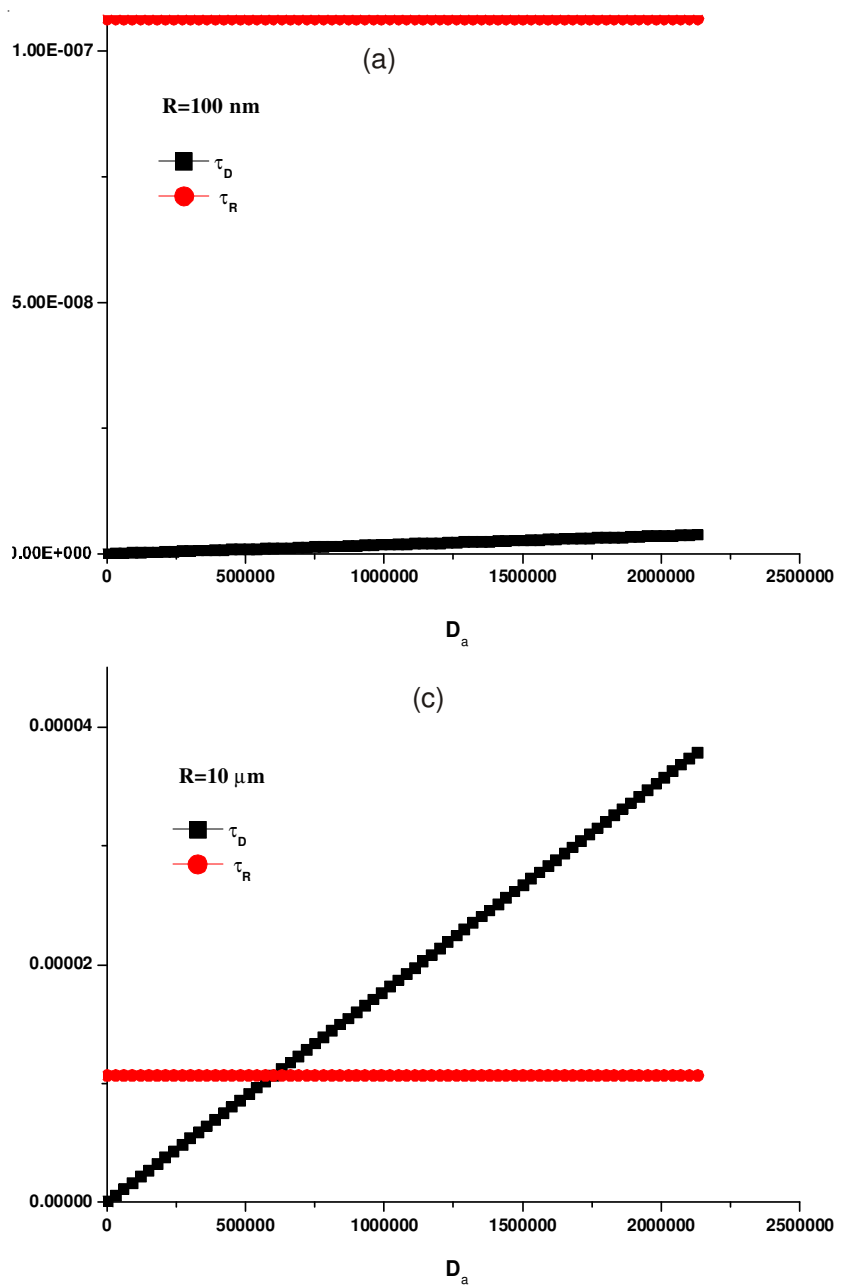

$\mathrm{R}=100 \mathrm{~nm}$ ), at all values of $\mathrm{D}_{\mathrm{a}}$ the amounts of $\tau_{\mathrm{r}}$ are greater than $\tau_{\mathrm{D}}$; this means that the reaction is rate-controller of hydrate formation. By increasing the initial radius of droplet to $100 \mu \mathrm{m}$ (Fig. 4-d), the increasing amount of $\tau_{\mathrm{r}}$ and $\tau_{\mathrm{D}}$ at $\mathrm{D}_{\mathrm{a}}$ $=7 \times 10^{5} \mathrm{~m}^{-1}$ was 0.986 and $11.518 \mathrm{~h}$ respectively. These results show that at low amounts of $\mathrm{D}_{\mathrm{a}}$, the chemical reaction between gas molecules and water droplet is rate-controller and at higher amounts of $\mathrm{D}_{\mathrm{a}}$, the diffusion of gas molecules through the hydrate layer is rate-controller of hydrate formation process. In Fig. 4-d $(\mathrm{R}=100 \mu \mathrm{m})$ it is observed that only at very low amounts of $\mathrm{D}_{a}$, the reaction is rate-controller and in wide range of $D_{a}$, the diffusion in gas layer is the controller of hydrate formation process. Generally, it can be concluded that by increasing the initial size of water droplet, the resistance of diffusion increases and in large size $(\mathrm{R}>100 \mu \mathrm{m})$ of water droplet, diffusion is the rate-controller of hydrate formation. These results are confirmed by eqns. (19) and (20). In these equations $\tau_{\mathrm{r}} \propto \mathrm{R}$ and $\tau_{\mathrm{D}} \propto \mathrm{R}^{2}$.

\section{Conclusion}

The kinetic of hydrate formation for water droplets was modeled by using shrinking core model. The main resistances in hydrate formation process are diffusion of gas molecules in hydrate layer and reaction of gas molecules with water droplet and the resistance of gas diffusion through the gas film is
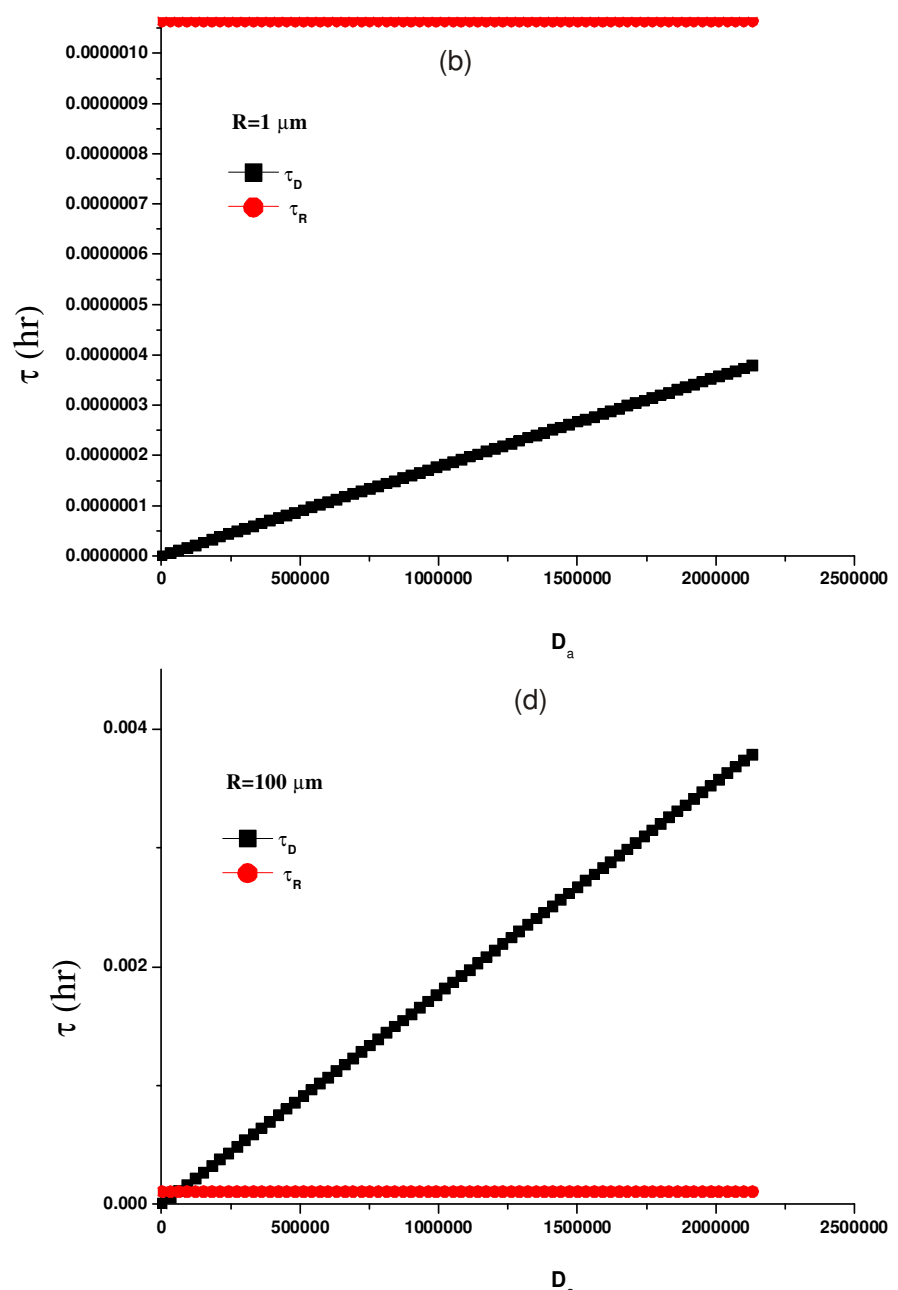

Fig. 5. Required time $(\tau)$ for complete conversion of water droplet to hydrate at 75 bar and $277.1 \mathrm{~K}$ and at various ; a) $\mathrm{R}=100 \mathrm{~nm}$; b) $\mathrm{R}=1 \mu \mathrm{m}$; c) $\mathrm{R}=10 \mu \mathrm{m}$; d) $\mathrm{R}=100 \mu \mathrm{m}$ 

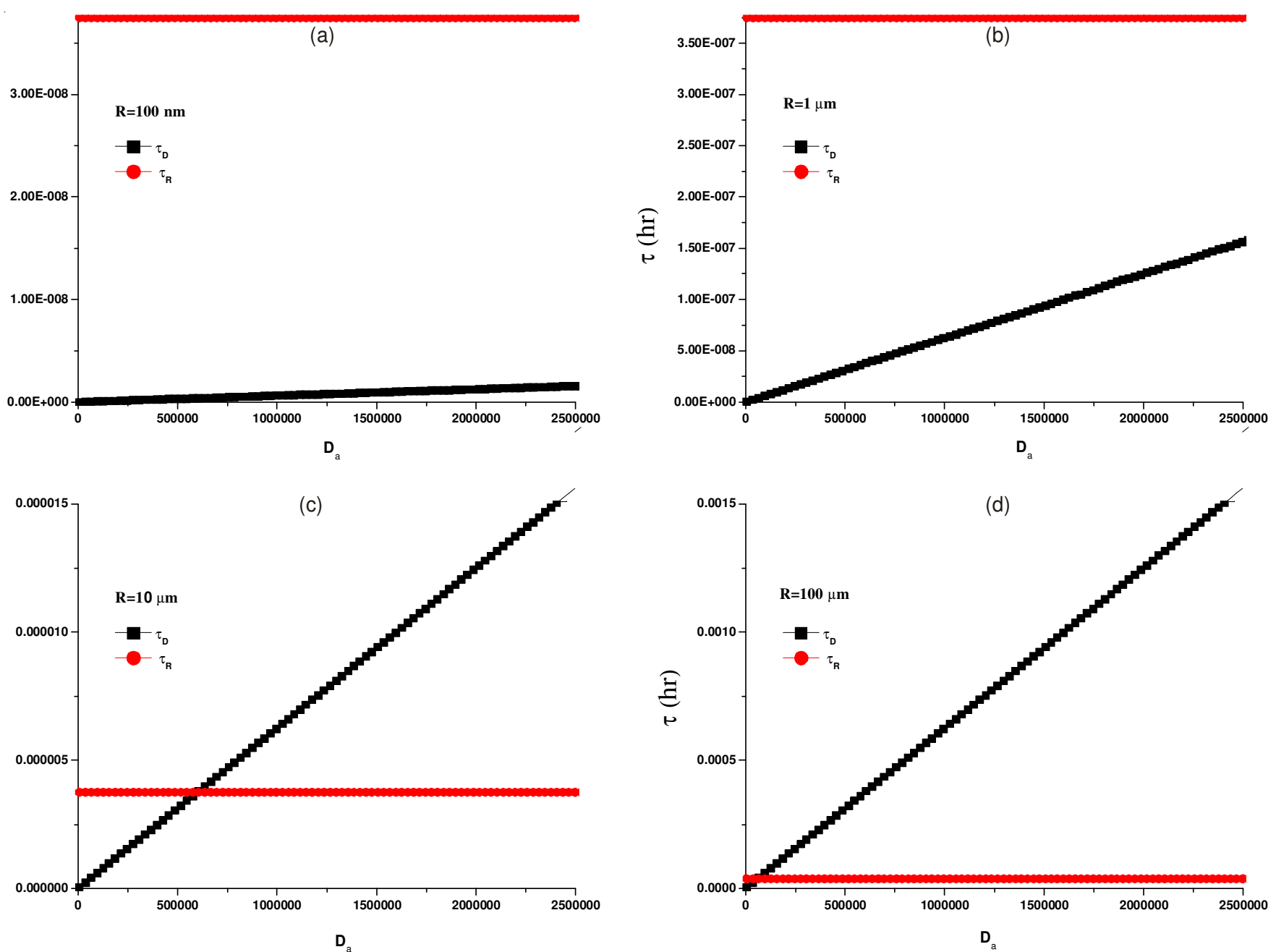

Fig. 6. Required time $(\tau)$ for complete conversion of water droplet to hydrate at 75 bar and $279.1 \mathrm{~K}$ and at various $D_{a} ;$ a) $R=100 \mathrm{~nm}$; b) $\left.R=1 \mu \mathrm{m} ; \mathrm{c}\right) \mathrm{R}=$ $10 \mu \mathrm{m} ; \mathrm{d}) \mathrm{R}=100 \mu \mathrm{m}$

negligible. The reaction rate constants of hydrate formation process were extracted from literature. For a wide range of effective diffusivity, the reaction and diffusion resistances were compared. By increasing the temperature, the effect of chemical reaction on the rate-controlling of hydrate formation increases. In the small water droplets $(\mathrm{R}<1 \mu \mathrm{m})$, the rate-controller of process is chemical reaction and in large droplets $(R>100$ $\mu \mathrm{m})$ diffusion of gas molecules in hydrate layer is the ratecontroller of hydrate formation process.

\section{ACKNOWLEDGEMENTS}

The financial support from the Research and Development Branch of National Iranian Gas Company is greatly appreciated.

\section{REFERENCES}

1. E.D. Sloan, Clathrate Hydrates of Natural Gases, Marcel Dekker, New York, edn. 2 (1998).

2. S.S. Fan, Technology in the Storage and Transport of Natural Gas Hydrate. Beijing: Chemical Industry Press (2005).

3. a) H. Ganji, M. Manteghian and H.R. Mofrad, Fuel Proces. Technol. 88, 891 (2007); b) H. Ganji, M. Manteghian, K.S. Zadeh, M.R. Omidkhah and H.R. Mofrad, Fuel, 86, 434 (2007).

4. a) A. Mohammadi, M. Manteghian and M. Mirzaei, Chem. Eng. Res. Des., 89, 421 (2011); b) A. Mohammadi, M. Manteghian, S.M. Hoseini Nasab and S.M. Mousavi, Petroleum Sci. Technol.,(Accepted); c) A. Mohammadi,
M. Manteghian and S.M. Mousavi, Petroleum Sci. Technol., (Accepted). 5. M. Manteghian, M. Azimi and J. Towfighi, (Coomunicated) (2011).

6. A. Jaworek, Powder Technol., 176, 18 (2007).

7. a) P. Englezos, N. Kalogerakis, P.D. Dholabhai and P.R. Bishnoi, Chem. Eng. Sci., 42, 2647 (1987); b) P. Englezos, N. Kalogerakis, P.D. Dholabhai and P.R. Bishnoi, Chem. Eng. Sci., 42, 2659 (1987);

8. P. Skovborg, H.J. Ng, P. Rasmussen and U. Mohn, Chem. Eng. Sci., 48, 445 (1993).

9. D.L. Zhong, D.P. Liu and Z.M. Wu, Modeling of Natural Gas Hydrate Formation on a Suspended Water Droplet, Proceedings of the 6th International Conference on Gas Hydrates (ICGH), Vancouver, British Columbia, CANADA (2008).

10. N. Gnanendran and R. Amin, Chem. Eng. Sci., 59, 3849 (2004).

11. M. Sugaya and Y.H. Mori, Chem. Eng. Sci., 51, 3505 (1996).

12. C.Y. Sun, G.J. Chen and T.M. Guo, Science in China (Series B), 46, 487 (2003).

13. M. Eaton, D. Mahajan and R. Flood, 56, 101 (2007).

14. J.D. Lee, R. Susito and P. Englezos, Chem. Eng. Sci., 60, 4203 (2005).

15. R. Ohmura, M. Sadatoshi, I. Sinya, T. Ebinuma and H. Narita, Formation and Growth of Structure-H Hydrate Crystals on a Water Drop in Contact with Methane Gas and Large-molecule Guest-substance Liquid, Proceedings of the $5^{\text {th }}$ International Conference on Gas Hydrate, Norway (2005).

16. O. Levenspiel, Chemical Reaction Engineering, Wiley, edn. 3 (1998).

17. S. Bergeron, J.G. Beltrán P. Servio, Fuel, 89, 294 (2010). 